\title{
Evaluation of Serum Bilirubin as a Predictive Marker for Simple and Complicated Appendicitis in Sulaimani Emergency Teaching Hospital
}

\author{
Seerwan Hama Shareef \\ Department of General Surgery \\ College of Medicine \\ University of Sulaimania \\ Sulaimania, Iraq \\ quaradaghi@gmail.com
}

\author{
Dara Ahmed Mohammed \\ Department of Anatomy \\ College of Medicine \\ University of Sulaimania \\ Sulaimania, Iraq \\ Dara.marif@univsul.edu.iq
}

\author{
Goran Ameer Ahmed \\ Department of General surgery \\ College of Medicine \\ University of Sulaimania \\ Sulaimania ,Iraq \\ Kurdagoran@gmail.com
}

\begin{abstract}
Diagnosis of acute appendicitis can be challenging in some cases as the differentials can be exhaustive. Previous studies have demonstrated that hyperbilirubinemia is a more specific marker for appendicitis than white blood count (WBC) and $C$ reactive protein (CRP), but this investigation is still not commonly used in the diagnostic workup of appendicitis. This prospective study aims to evaluate serum bilirubin as a laboratory marker for simple and complicated appendicitis. We also investigated the diagnostic value of bilirubin in acute appendicitis and compared it with the WBC. In this prospective study, all patients who underwent appendicectomy at the Sulaimani Emergency Teaching Hospital between $1^{\text {st }}$ November 2016 to $1^{\text {st }}$ January 2017 were included. Preoperative total serum bilirubin was measured and compared with the final histopathology report. Patients were divided into 3 groups: non-inflamed appendix, simple appendicitis and complicated appendicitis. One hundred and 75 patients were analysed, 90 of them were females and 85 were males. Hyperbilirubinemia was found in $63 \%$ of patients with complicated appendicitis $(p=0.001)$. Mean of bilirubin was significantly different between patients with complicated appendicitis and non-complicated appendicitis (1.101 vs $0.75 \mathrm{mg} / \mathrm{dl}$; $p=0.0017)$. Bilirubin had a higher specificity (85\%) than WBC (36\%), but a lower sensitivity (63\% vs 89\%) for differentiating complicated appendicitis. Patients with suggestive features of acute appendicitis and raised serum bilirubin indicate a complicated case requiring early intervention to prevent peritonitis and septicaemia. Hyperbilirubinemia is a good indicator for complicated appendicitis and serum bilirubin measurement can be included in the work up of patients with suspected appendicitis.
\end{abstract}

Keywords: Acute appendicitis, Appendectomy, Hyperbilirubinaemia, Diagnostic markers.

\section{INTRODUCTION}

Acute appendicitis (AA) is one of the most common surgical emergencies. Appendectomy is among the most frequently performed emergency operations worldwide [1-3]. The first appendectomy was performed by
Claudius Amyand, on a boy (11 years old) in 1736 [4]. The lifetime risk of developing appendicitis is $8.6 \%$ for males and $6.7 \%$ for females. The highest incidence is in the second and third decades of life [5]. It is a polymicrobial infection with some series reporting up to 14 different organisms cultured in patients with perforation. The main organisms cultured from peritoneal fluid of the patients, are Escherichia coli and Bacteroides fragilis [5].

Obstruction of the lumen due to fecaliths or hypertrophy of lymphoid tissue is proposed as the main etiologic factor in AA [1,5]. Other less common causes are tumours, vegetable and fruit seeds, and intestinal parasites [5]. The obstruction causes elevation of intraluminal pressure. This ultimately leads to venous outflow obstruction, ischaemia, loss of epithelial integrity and bacterial invasion of appendiceal wall. As the pathology progresses, gangrene and perforation of the appendix occur forming a periappendicular abscess or local/generalized peritonitis $[4,6]$.

Diagnosis of AA is made primarily on the basis of the history and the physical examination [6,7]. However, it is not always straight forward, as there are a number of causes leading to pain in right iliac fossa (RIF) particularly in female patients [8]. The variation in the pathophysiological development of the disease, along with the wide range of possible locations of the organ explain why only $50 \%$ of patients have a classical history on presentation [9]. In fact, the differentials include almost all causes of abdominal pain. A useful rule is never to place appendicitis lower than second in the differential diagnosis of acute abdominal pain in a previously healthy person [10].

Aside from symptomatology and specific physical examination findings, ultrasonography and computed tomography (CT) scans have become useful tools, with accuracies up to 85 to $99 \%$ [11-14]. However, these diagnostic adjuncts may be expensive, may involve a high radiation exposure, and may not always have accurate and reproducible results [15]. Scoring systems such as the Alvarado Score and the Appendicitis Inflammatory Response Score have been devised to assist in the diagnosis [16-22]. These scores are based on clinical presentations, white blood count (WBC) and/or C-reactive protein (CRP) [23]. The diagnostic and 
discriminatory value of WBC and CRP in AA has been studied extensively but it remains controversial [24-28]. Furthermore, some studies have shown that neither of these markers are a diagnostic indicator nor specific for AA [29].

Jaundice in the context of appendicitis has been well described in the literature over 60 years ago [30]. In 1969, Miller and Irvine showed in a prospective series of appendectomies that jaundice in patients with AA correlated with peritoneal positive cultures for E. coli [31]. More recent studies suggest that elevated serum bilirubin in patients with clinically suspected appendicitis may be a predictor for appendiceal perforation with high specificity and positive predictive values [29,32-39]. Furthermore, a study showed that serum bilirubin has been found to have a sensitivity of $70 \%$ and specificity of $86 \%$ for perforated appendicitis [34]. Moreover, Emmanuel A et al concluded that bilirubin is a specific marker for simple AA, not necessarily complicated, with a good positive predictive value, and suggested that it should be included in the overall assessment of suspected patients of having appendicitis [29]. The recent attention to the association between hyperbilirubinemia and appendicitis could be explained by the over ordering of "routine" blood tests in the emergency department. As a result, more studies are needed to test this hypothesis [8].

Hyperbilirubinemia, defined as elevated serum bilirubin, either because of increased production or impaired clearance, is not well known as a laboratory marker for complicated appendicitis. Both mechanisms, increase production and alteration of bilirubin clearance, might play a role in the observed hyperbilirubinemia of patients with appendiceal perforation [34]. As previously mentioned, the most common bacterial species which is cultured from the appendiceal wall of patients with AA has been E. coli and Bacteroides fragilis [5,34], both of which have been shown to cause a portal sepsis and interfere with hepatocyte microcirculation, inducing sinusoidal damage as shown in a rat liver model [40,41]. E. coli-associated lipopolysaccharides have been shown to have an effect on hepatocyte uptake and excretion of bile acids [42]. Also, E. coli endotoxin leads to a dosedependent bile stasis, which has been shown in a rat liver model [43]. In addition, E. coli infection has been shown to induce hemolysis of erythrocytes [44]. The resulting inflammatory-mediated cholestasis, along with the proposed hemolysis leads to an increased bilirubin load in infected individuals, which likely promotes hyperbilirubinemia [34,42-44]. Histopathologic studies are considered as the gold standard for diagnosis of AA [45]. The criterion standard is neutrophilic infiltration of muscularis propria [46]. Various sources have divided AA into two broad categories: uncomplicated or simple, with no gangrene, perforation or abscess formation, and complicated (perforated/gangrenous) appendicitis [5,10,29,38].

Recent evidence from a large multi-center study has suggested that patients with simple appendicitis can undergo short in-hospital observations prior to having their appendicectomies [47]. Some studies are even suggesting that non-operative management with antibiotics is possible [48-51]. However, urgent surgery is still the treatment of choice for complicated (gangrenous/perforated) appendicitis due to the higher rate of complications and the need to control the source of sepsis $[5,10,39]$. Therefore, it is important to classify patients into those with simple appendicitis who can undergo surgery at a safe opportunity or even managed non-operatively and those with complicated appendicitis that require surgery more urgently [39]. Presence or absence of hyperbilirubinemia may aid in the distinction between these two groups of patients [29]. Diagnosing AA clinically still remains challenging in some instances. The presence of hyperbilirubinemia, that is not explained by liver disease or biliary disease, as a predictor of appendicitis has been studied so that serum bilirubin levels measured upon admission can be used in conjunction with other diagnostic tests such as ultrasonography and CT [37]. Total serum bilirubin is a commonly requested blood test. Unlike imaging modalities, it is relatively inexpensive, and carries no risks such as irradiation from CT scans. A safe, cheap, rapid, widely available, accurate diagnostic marker for appendicitis would be useful to the emergency general surgeon to manage suspected appendicitis [38].

\section{METHODS AND MATERIALS}

This single-center cohort, prospective study was conducted in Sulaimani Surgical Teaching Hospital from $1^{\text {st }}$ November 2016 to $1^{\text {st }}$ January 2017 . To conduct this study, ethics approval was obtained from Kurdistan Board for Medical Specialties (KBMS) ethics committee, and informed consent was obtained from the patients. A total of 211 patients, who underwent appendicectomy at the emergency department of Sulaimani Teaching Hospital were initially enrolled in the study. The diagnosis of AA was made with a combination of clinical, laboratory and imaging findings. The patients underwent emergency or urgent appendicectomy according to their condition. All appendicectomies were carried out by an open method. Collected data included patients' age, gender, preoperative WCC, CRP (not always present), ultrasound finding and operative finding. Total serum bilirubin (TSB) was also performed preoperatively on the collected blood sample. Determination of TSB was done using Kenza 240TX machine (Biolabo Diagnostics). The normal levels for the above markers based on the reference ranges of the hospital, were: WCC 4-10 x 109cells/L, CRP <10mg/L, and bilirubin $0.2-1.1 \mathrm{mg} / \mathrm{dl}$.

Inclusion criteria: All patients admitted with a provisional diagnosis of appendicitis and who underwent appendicectomy during the study period. Exclusion criteria were: history of liver or biliary tract disease (including viral hepatitis positive patients), history of hemolytic disease, patients who were taking known hepatotoxic medications, and patients who did not have preoperative serum bilirubin for technical reasons. All the specimens were analysed by histopathological examination. Accordingly, patients were divided into three groups according to their clinical and histological findings. Group 1 comprised of patients with noninflamed appendices, group 2 comprised of those with uncomplicated acute appendicitis or reactive lymphoid 
hyperplasia, and group 3 comprised of patients with a perforated or gangrenous appendix (Complicated appendicitis). Comparisons were made between each group and their respective laboratory markers.

Statistical analysis: Statistical Package for the Social Science (SPSS) version 20.0.0 used. A $p$ value of $<0.05$ was considered a statistically significant.

\section{RESULTS}

A total of 211 patients who underwent appendicectomy for acute appendicitis were included in the study. From all, 36 patients could not fulfill the criteria and were excluded. Two patients had thalassemia major, two patients were hepatitis B positive and 32 patients did not have their serum bilirubin measured preoperatively, so they were excluded. The remaining of 175 patients were analysed. Out of the 175 included patients, 90 patients were female $(51.4 \%)$ and 85 were male $(48.6 \%)$ (Table 1).

Table 1: shows gender distribution of the study population.

\begin{tabular}{|c|c|c|}
\hline Gender & Frequency & Percent \\
\hline Femal & 90 & 51.4 \\
\hline Male & 85 & 48.6 \\
\hline Total & 175 & 100.0 \\
\hline
\end{tabular}

The age of the patients ranged from 5 to 56 years with a mean of 24.9 years (SD: +/- 10.42). Figure 1 shows the age and gender distribution with the most common age group between 11-20 years old (36\%).

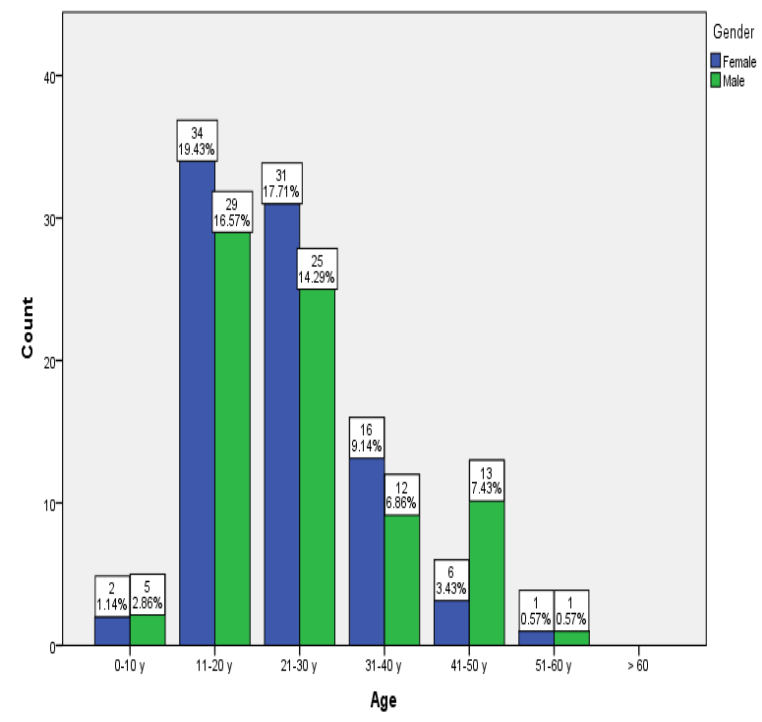

Figure 1: Bar chart shows age and gender distribution of the participants.

According to the operative finding and the final histopathology report: 34 patients had normal appendices (19\%), 103 patients (59\%) had uncomplicated acute appendicitis or reactive lymphoid hyperplasia, and 38 patients $(22 \%)$ had complicated appendicitis (perforated/ gangrenous), as shown in (Table 2).
Table 2: shows comparison between gender and the final diagnosis.

\begin{tabular}{|c|c|c|c|c|}
\hline Frequency & Percent & Female & Male & Frequency \\
\hline Normal & 34 & $19.4 \%$ & 22 & 12 \\
\hline Uncomplicated & 103 & $58.9 \%$ & 61 & 42 \\
\hline Complicated & 38 & $21.7 \%$ & 7 & 31 \\
\hline Total & 175 & 100.0 & $\begin{array}{c}90 \\
(51.4 \%)\end{array}$ & $\begin{array}{c}85 \\
(48.6 \%)\end{array}$ \\
\hline
\end{tabular}

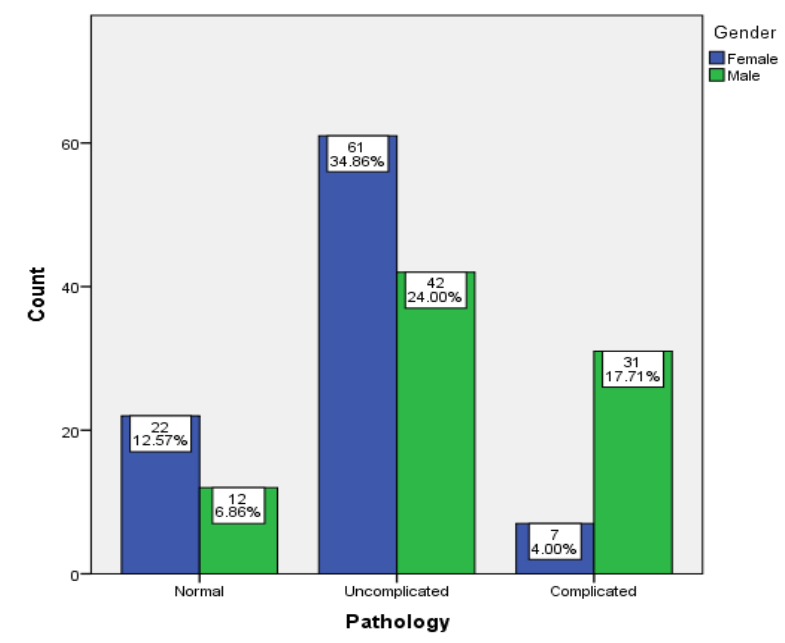

Figure 2: shows comparison between gender and the final diagnosis.

Overall, TSB was elevated in 41 patients $(23.5 \%)$. In Group 1, 2 out of 34 patients had raised preoperative TSB (6\%), in group 2, 15 patients out of $103(14.6 \%)$, and group 3, 24 out of 38 patients $(63 \%)$. This difference was statistically significant ( $p$ value $=0.001)$, as demonstrated in (Table 3).

The mean TSB of the groups 1,2 and 3 were $0.54,0.75$, and $1.101 \mathrm{mg} / \mathrm{dl}$ respectively. This shows that the value of TSB increased with progression of appendicitis severity. Using unpaired t-test, comparing the differences in mean TSB between patients with normal histology and those with simple appendicitis showed no statistically significant difference ( $p$-value $<0.05$ ). While the difference in mean bilirubin between uncomplicated appendicitis and complicated appendicitis was statistically significant ( $p$-value $<0.01$ ).

Table 3: correlation between TSB and final diagnosis

\begin{tabular}{|c|c|c|c|}
\hline \multirow{4}{*}{ Final diagnosis } & Normal & Elevated & \multirow{2}{*}{ Percent } \\
\cline { 2 - 4 } & Count & Count & \\
\hline Normal & 32 & 2 & $6 \%$ \\
\hline Uncomplicated & 88 & 15 & $14.6 \%$ \\
\hline Complicated & 14 & 24 & $63 \%$ \\
\hline TOTAL & 134 & 41 & $23.5 \%$ \\
\hline
\end{tabular}




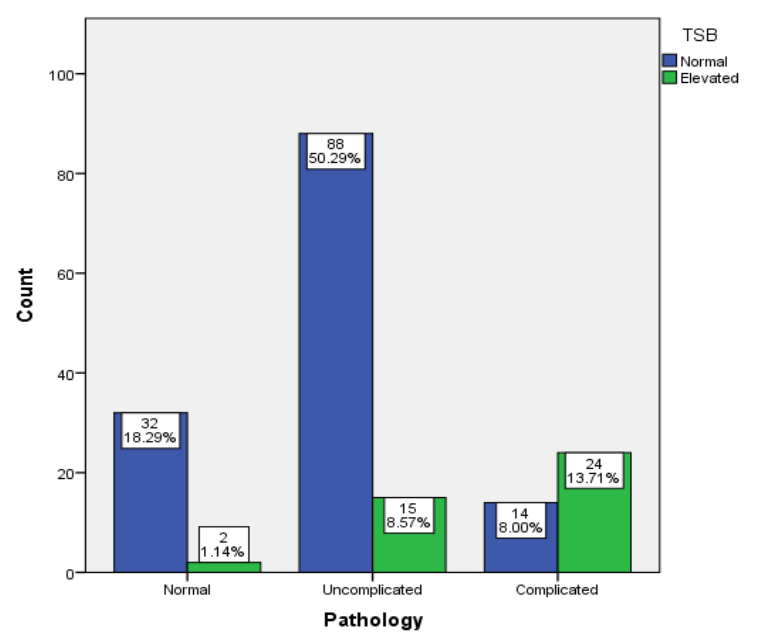

Figure 3: correlation between TSB and clinicopathologic classes.

To analyse the diagnostic value of serum bilirubin in appendicitis, we compared patients with appendicitis (complicated and uncomplicated) to the patients with normal histopathology. We found that a specificity of $94 \%$ for hyperbilirubinemia in appendicitis, with a positive predictive value (PPV) of $95 \%$. Sensitivity and negative predictive value (NPV) were lower (28\% and $24 \%$ respectively). White blood count had a higher sensitivity $(71 \%)$ but a lower specificity (47\%). Details are shown in (Table 4).

Table 4: Shows sensitivity, specificity, PPV and NPV of WBC and TSB for appendicitis Vs Normal histology

\begin{tabular}{|c|c|c|c|c|}
\hline & $\begin{array}{c}\text { Sensitivity } \\
\%\end{array}$ & $\begin{array}{c}\text { Specificity } \\
\%\end{array}$ & $\begin{array}{c}\text { PPV } \\
\%\end{array}$ & $\begin{array}{c}\text { NPV } \\
\%\end{array}$ \\
\hline $\begin{array}{c}\text { Serum } \\
\text { Bilirubin }\end{array}$ & $28 \%$ & $94 \%$ & $95 \%$ & $24 \%$ \\
\hline WBC & $71 \%$ & $47 \%$ & $85 \%$ & $28 \%$ \\
\hline
\end{tabular}

Hyperbilirubinemia in complicated appendicitis vs simple appendicitis had a specificity of $85 \%$ for perforated /gangrenous appendicitis, a sensitivity of $63 \%$. Bilirubin had a higher specificity $(85 \%)$ than WBC $(36 \%)$, but a lower sensitivity $(63 \%$ vs $89 \%$ respectively). Details are shown in (Table 5).

Table 5: Shows sensitivity, specificity, PPV and NPV of WBC and TSB for Complicated Appendicitis vs simple appendicitis

\begin{tabular}{|c|c|c|c|c|}
\hline & $\begin{array}{c}\text { Sensitivity } \\
\%\end{array}$ & $\begin{array}{c}\text { Specificity } \\
\%\end{array}$ & $\begin{array}{c}\text { PPV } \\
\%\end{array}$ & $\begin{array}{c}\text { NPV } \\
\%\end{array}$ \\
\hline $\begin{array}{c}\text { Serum } \\
\text { Bilirubin }\end{array}$ & $63 \%$ & $85 \%$ & $62 \%$ & $86 \%$ \\
\hline WBC & $89 \%$ & $36 \%$ & $34 \%$ & $90 \%$ \\
\hline
\end{tabular}

By inspecting the mean values for bilirubin and WBC within our three groups, we found that all values increased with increasing appendicitis severity. This difference was statistically significant $(\mathrm{p}<0.0001)$. Details are given in (Table 6).

Table 6: Mean marker values for each study group

\begin{tabular}{|c|c|c|c|c|}
\hline Marker & Group 1 & Group 2 & Group 3 & p Value \\
\hline Bilirubin & 0.54 & 0.75 & 1.101 & $\mathrm{p}<0.0001$ \\
\hline WBC & 10.52 & 11.80 & 15.47 & $\mathrm{p}<0.0001$ \\
\hline
\end{tabular}

\section{DISCUSSION}

Previous studies have found hyperbilirubinaemia to be a marker with high specificity for perforated appendicitis [29, 32-39]. Serum bilirubin levels in the adult surgical population are usually raised due to liver or gallbladder problems. Gilbert's syndrome may cause an idiopathic, benign, isolated unconjugated hyperbilirubinemia. However, the prevalence of Gilbert's syndrome is expected to be around 3-8\% [33], which is considerably less than the ratio in simple appendicitis in the current study (15\%) and perforated appendicitis (63\%). Gilbert's syndrome may explain the finding of this current study of hyperbilirubinemia in 2 patients $(6 \%)$ with ultimately normal appendix histology. Mean age, age distribution and gender distribution was similar to most other studies $[8,23,29,34,38]$. Rate of negative appendectomy was (19.4\%) in comparison to D'Souza et al (22\%) [38], Emmanuel et al (18\%) [29] and Atahan et al (14\%) [35]. But it was lower than Panagiotopoulou et al (33.9\%) [53], who conducted a large retrospective study analysing 1,169 patients. Their explanation was that they removed all appendices during diagnostic laparoscopy for RIF pain if no other pathology was found. Our figures are within the acceptable rate of negative appendectomy worldwide. Negative appendectomy was more commonly performed on females. This is again in accordance with findings in the literature [8, 23, 34].

The rate of complicated appendicitis namely gangrenous/ perforated appendicitis is commonly around $25 \%$ [5], varies greatly in the literature. Panagiotopoulou et al reported a rate as low as $3.5 \%$, while others reported figures ranging from $14 \%$ - $26 \%$ $[8,23,33,38,39,53]$. The current study showed a rate of complicated appendicitis of $21.7 \%$. Males outnumbered females in the complicated group of patients, which goes with findings of Ran Hong Y et al [23], Estrada et al [33], and Sand et al [34].

With regard to the predictive value of hyperbilirubinemia for simple and complicated appendicitis, our study showed that hyperbilirubinemia was more common in patients with simple appendicitis group than those with normal appendix histology (15\% vs $6 \%, \mathrm{p}=0.06)$. But this difference was not statistically significant in the study. Also, mean bilirubin levels were higher for patients with appendicitis than patients with normal appendices ( 0.54 vs $0.75, \mathrm{p}=0.072)$. This finding is similar to that of Estrada et al [33] and Sand et al [34], who could not find a statistically significant relationship between hyperbilirubinemia and simple appendicitis. However, D'Souza et al found a statistically significant difference by including gangrenous appendicitis in the "simple appendicitis" group and also including a group of patients with RIF pain managed conservatively [38]. 
Emmanuel A et al showed that hyperbilirubinaemia is a significant marker for simple acute appendicitis and not only appendiceal perforation [29]. These findings can be explained by including a larger number of patients from both groups. In contrast, in our study hyperbilirubinemia was found in $63 \%$ of patients in the complicated appendicitis group, which is highly significant ( $\mathrm{p}$ value $=0.001$ ). Furthermore, mean TSB in group 3 patients (1.101) was significantly higher than mean of group 1 and 2 ( $\mathrm{p}$ value =0.0017). This reflects that hyperbilirubinemia maybe secondary to appendicitis. In fact, the value of TSB increases with progression of appendicitis severity. This is supported by Estrada et al who observed that the prevalence of a positive peritoneal culture was significantly higher in patients with gangrenous/perforated appendicitis [33].

The development of jaundice in sepsis is well recognised and has been associated with a variety of causative bacteria, gram-negative bacteria being most commonly implicated [52]. Several mechanisms leading to hyperbilirubinaemia in systemic infections have been described. Haemolysis causes an increased bilirubin load and has been associated with several bacteria including E. coli [44, 52]. Also, bacterial endotoxin causes a cytokine mediated inhibition of bile salt transport mechanisms, leading to cholestasis [42]. This dosedependent cholestatsis explains why serum bilirubin increases with appendicitis severity. Escherichia coli is associated with the endotoxin lipopolysaccharide and is the most common organism cultured from intraperitoneal fluid in appendicitis [40]. Hyperbilirubinaemia presumably occurs in appendicitis as a result of bacteraemia or endotoxaemia, which could occur both in simple appendicitis and perforated or gangrenous appendicitis but more commonly in the latter group [29].

Several studies have shown that the hyperbilirubinemia observed in patients with appendicitis is isolated with no elevation in the other liver enzymes [8,29,32,33,34]. Also, the hyperbilirubinemia was found to be of mixed type (both conjugated and unconjugated) by Chaudhary $\mathrm{P}$ et al [37]. For our secondary aim, we found that TSB has a high specificity (94\%) and PPV (95\%) for appendicitis in general, but has a lower sensitivity than WBC ( $28 \%$ vs. $71 \%$ ). Furthermore, hyperbilirubinemia has a higher specificity $(85 \%)$ and NPV (86\%) than WBC but a lower sensitivity (63\% vs 89\%) for differentiating simple from complicated appendicitis. These findings are supported by the findings of D'Souza et al [38] and Emmanuel et al [29]. This confirms the use of hyperbilirubinaemia as a confirmatory test rather than to exclude appendicitis.

These findings have two potential benefits. Firstly, serum bilirubin can be used in female patients who present with RIF pain, whose clinical findings may mimic other causes. Secondly, in patients who are diagnosed clinically as AA, the finding of hyperbilirubinemia may indicate a perforated appendix and thus expedite surgery. Keeping in mind that the rate of morbidity and mortality in patients operated on for perforated appendicitis is about $5 \%$, which is higher than for patients operated on for appendicitis without perforation [5]. There were some limitations to this study. Firstly, the relatively small sample compared to the frequency of the appendicitis. Our sample size was limited by the short duration of sample collection. Also, preoperative CRP values were only available in a few patients, so they were not included in the analysis.

\section{Conclusion}

Our findings suggest that assessment of bilirubin level may help in the diagnosis of acute appendicitis. This is particularly important in patients with less typical presentation or in female patients with a differential diagnosis of a gynaecologic pathology. We recommend serum bilirubin measurement in the workup of patients presenting with atypical features of AA. In addition, hyperbilirubinemia in patients with appendicitis indicates a higher likelihood of a perforated or gangrenous appendix. Therefore, patients with right iliac fossa pain and hyperbilirubinemia warrant early surgical intervention. Serum bilirubin was found to be a more specific marker for complicated appendicitis than WBC with a high negative predictive value and acceptable sensitivity. However, diagnosis of appendicitis remains multifactorial and serum bilirubin should be used together with clinical findings and other routine laboratory tests.

\section{REFRENCE}

[1] A, Cusheiri, PA, Grace, A, "Darzi, et al. Disorders of small intestine and vermiform" appendix. In: Cuschieri A, Grace PA, Darzi A, et al, editors. Clinical Surgery. 2nd ed. UK: Blackwell Publishing Ltd; 2003;405.

[2] S. Paterson - Brown. "Acute appendicitis. In: Paterson-Grown Simon, Ellis Brian W, Paterson-Brown Simon, editors. Hamilton Bailey's Emergency Surgery. 13th ed. London: Arnold; 2003, 399.

[3] Smith PH. The diagnosis of appendicitis. Postgrad Med J 1965 , pp. (4) 2-5.

[4] WH, Peranteau, DS, Smink. Appendix, Meckel's and other small bowel diverticula. In: Zinner M, Ashley S., editors. Maingot's Abdominal Operations. 12th Edition. USA: McGraw-Hill Professional. 2012, pp. 623-40

[5] BM, Jaffe. DH, Berger. The Appendix. In: Brunicardi FC, et al. editors. Schwartz's principles of surgery. 9th ed. USA: McGrawHill. 2010, pp.1073-1089

[6] A, Cuschieri. Disorders of the small intestine and vermiform appendix. In: Cuschieri A, Hanna GB, editors. Essential surgical practice: higher surgical training in general surgery. 5th edition. UK: Crc Press.2015, pp. 927-30

[7] F, Nabipour. BD, Mohammad. Histopathological feature of acute appendicitis in Kerman-Iran from 1997 to 2003. Am J Environ Sci. 2005, pp1:130-2.

[8] YA, Al-Abed. N, Alobaid. F, Myint "Diagnostic markers in acute appendicitis". The American Journal of Surgery. 2015 Jun 30;209(6), pp.1043-7.

[9] R, Marudanayagam. GT, Williams. "Rees BI. Review of the pathological results of 2660 appendicectomy specimens". Journal of gastroenterology. 2006 Sep 1;41(8), pp745-9.

[10] J, Maa. KS, .Kirkwood. "The Appendix. In: Townsend Jr CM, Beauchamp RD, Evers BM, Mattox KL. editors. Sabiston textbook of surgery". 19th ed. USA: Elsevier Health Sciences.2012, pp.1279-93

[11] C, Franke. H, Bohner. Q,Yang. C, Ohmann. HD, Roher. "Ultrasonography for diagnosis of acute appendicitis: results of a prospective multicenter trial. Acute Abdominal Pain Study Group". World J Surg 1999, pp.23:141-6.

[12] P, Poortman. PN, Lohle. CM, Schoemaker HJ, Oostvogel HJ, Teepen. KA, Zwinderman et al. "Comparison of CT and sonography in the diagnosis of acute appendicitis: a blinded prospective study". AJR Am J Roentgenol 2003, pp181-186.

[13] S, Cakirer. M, Basak. B, Colakoglu. M, Bankaoglu "Diagnosis of acute appendicitis with unenhanced helical CT: a study of 130 patients". Emerg Radiol 2002(9), pp155-156

[14] MJ, Lane. DM, Liu. Huynh MD, Jeffrey RB Jr, Mindelzun RE, Katz DS. Suspected acute appendicitis: nonenhanced 
helical CT in 300 consecutive patients. Radiology 1999; 213:341-6.

[15] PF, Jones. "Suspected acute appendicitis: trends in management over 30 years" British journal of surgery. 2001 Dec 1;88(12), pp.1570-1577.

[16] A, Alvarado"A practical score for the early diagnosis of acute appendicitis" Ann Emerg Med 1986(15), pp557-564.

[17] CD, Douglas"Macpherson NE, Davidson PM, Gani JS. Randomised controlled trial of ultrasonography in diagnosis of acute appendicitis, incorporating the Alvarado score" BMJ 2000(321), pp919-922.

[18] TD, Owen" Williams H, Stiff G, Jenkinson LR, Rees BI. Evaluation of the Alvarado score in acute appendicitis" J R Soc Med 1992(85), pp.87-88.

[19] MJ, Lamparelli. HM, Hoque, CJ, Pogson "Ball AB. A prospective evaluation of the combined use of the modified Alvarado score with selective laparoscopy in adult females in the management of suspected appendicitis" Ann R Coll Surg Engl 2000(82), pp.192-195.

[20] SM, de Castro, C, Unlu. EP, Steller "van Wagensveld BA, Vrouenraets BC. Evaluation of the appendicitis inflammatory response score for patients with acute appendicitis" World J Surg 2012(36), pp.1540-1545.

[21] M, Andersson. RE, Andersson "The appendicitis inflammatory response score: a tool for the diagnosis of acute appendicitis that outperforms the Alvarado score" World J Surg 2008 (32), pp.1843-1849.

[22] R, Ohle. F, O'Reilly. KK, O'Brien. T, Fahey. BD, Dimitrov."The Alvarado score for predicting acute appendicitis: a systematic review" BMC Med 2011(9), pp.139143

[23] YR, Hong Chung, JW, Kim. CI, Kwon. DH, Ahn, SW, Kwon., SK, Kim. "Hyperbilirubinemia is a significant indicator for the severity of acute appendicitis. Journal of the Korean Society of Coloproctology". 2012, (5), pp. 247-252.

[24] B, Vermeulen, A, Morabia, PF, Unger. "Influence of white cell count on surgical decision making in patients with abdominal pain in the right lower quadrant" The European journal of surgery= Acta chirurgica. 1995 (7), pp. 483-486.

[25] D, Birchley. "Patients with clinical acute appendicitis should have pre-operative full blood count and C-reactive protein assays. The Annals of The Royal College of Surgeons of England". 2006, (1), pp.27-32.

[26] H, Körner, JA, Söreide, K, Söndenaa. "Diagnostic accuracy of inflammatory markers in patients operated on for suspected acute appendicitis: a receiver operating characteristic curve analysis. The European journal of surgery". 1999 165(7), pp.679-685.

[27] PG, Vaughan-Shaw, JR, Rees, E, Bell, M, Hamdan, T, Platt "Normal inflammatory markers in appendicitis: evidence from two independent cohort studies"JRSM short reports. 2011 May 2(5), pp. 43-45.

[28] RE, Andersson. "Meta-analysis of the clinical and laboratory diagnosis of appendicitis" British Journal of Surgery. 2004 91(1), pp. 28-37.

[29] A, Emmanuel, P, Murchan, I, Wilson, P, Balfe. "The value of hyperbilirubinaemia in the diagnosis of acute appendicitis" Annals of the Royal College of Surgeons of England. 2011;93(3), pp. 213-215.

[30] TA, Ogilvie. "Acholuric jaundice and appendicitis" Br J Surg 1951(38), pp. 529-530

[31] DF, Miller, RW, Irvine. Jaundice in acute appendicitis. Lancet 1969(1), pp. 321-323.

[32] S, Khan.'Elevated serum bilirubin in acute appendicitis: a new diagnostic tool" Kathmandu University Medical Journal. 2008(6), pp.161-5.

[33] JJ, Estrada, M, Petrosyan, J, Barnhart, M, Tao, H, Sohn, S, Towfigh, RJ, Mason. "Hyperbilirubinemia in appendicitis: a new predictor of perforation" Journal of Gastrointestinal Surgery. 2007 11(6), pp.714-718.

[34] M, Sand. FG, Bechara, T, Holland-Letz, D, Sand, G, Mehnert, B, Mann.'Diagnostic value of hyperbilirubinemia as a predictive factor for appendiceal perforation in acute appendicitis". The American Journal of Surgery. 2009 198(2), pp.193-198.

[35] K, Atahan, O, Üreyen, E, Aslan, M, Deniz, A, Cökmez, S, Gür, A, Avci, E, Tarcan. "Preoperative diagnostic role of hyperbilirubinaemia as a marker of appendix perforation" Journal of International Medical Research. 2011 39(2), pp.609618
36] DR, McGowan, HM, Sims, I, Shaikh, M, Uheba. "The value of hyperbilirubinaemia in the diagnosis of acute appendicitis". Annals of the Royal College of Surgeons of England. 2011 93(6), pp. 498.

[37] P, Chaudhary, A, Kumar, N, Saxena, UC, Biswal. "Hyperbilirubinemia as a predictor of gangrenous/perforated appendicitis: a prospective study. Annals of gastroenterology" quarterly publication of the Hellenic Society of Gastroenterology. 2013 (4), pp325

[38] N, D'Souza, D, Karim, R, Sunthareswaran. "Bilirubin; a diagnostic marker for appendicitis". International Journal of Surgery. 2013 11(10), pp.11-14

[39] AC, Chambers, SL, Bismohun, H, Davies, AV, White P, Patil. "Predictive value of abnormally raised serum bilirubin in acute appendicitis: a cohort study" International Journal of Surgery. 2015 (13), pp. 207-210

[40] EJ, Baron, R, Bennion, J, Thompson, C, Strong, P, Summanen, M, McTeague, SM, Finegold. "A microbiological comparison between acute and complicated appendicitis" Clinical Infectious Diseases. 1992 14(1), pp. 227-231.

41] RD, Rink, CR, Kaelin, B, Giammara, DE, Fry. "Effects of live Escherichia coli and Bacteroides fragilis on metabolism and hepatic pO2. Circulatory shock". 1980 (5), pp. 601-611.

[42] RM, Green, DA, Beier, JL, Gollan. "'Regulation of hepatocyte bile salt transporters by endotoxin and inflammatory cytokines in rodents" Gastroenterology. 1996 111(1), pp. 193-198

[43] R, Utili, CO, Abernathy, HJ, Zimmerman. "Cholestatic effects of Escherichia coli endotoxin endotoxin on the isolated perfused rat liver. Gastroenterology" 1976 70(2), pp.248-253

[44] A, Shander. "Anemia in the critically ill" Crit Care Clin 2004(20), pp. $159-178$.

[45] J, Rosai. Gatrointestinal tract. In: J Rosai, LV Ackerman, editors. Rosai and Ackerman's surgical pathology. 9th ed. Edinburgh: Mosby Co.2004, pp.757-61

46] JM, Crawford, V, Kumar. The oral cavity and the gastrointestinal tract. In V, Kumar., RS, Cotran, and Robbins SL editors. Robbins Basic Pathology, 7th ed. New York: Saunders. 2003, pp. 588-9.

[47] A, Bhangu." Safety of short, in-hospital delays before surgery for acute appendicitis: multicentre cohort study, systematic review, and meta-analysis". Annals of surgery. 2014. (5), pp. 894-903.

[48] KK, Varadhan, DJ, Humes, KR, Neal, DN, Lobo. “Antibiotic therapy versus appendectomy for acute appendicitis: a metaanalysis" World journal of surgery. 2010, 34(2), pp. 199-209

[49] J, Hansson, U, Körner, A, Khorram-Manesh, A, Solberg, K, Lundholm. "Randomized clinical trial of antibiotic therapy versus appendicectomy as primary treatment of acute appendicitis in unselected patients" British journal of surgery. 2009, 96(5), pp. 473-81

[50] S, Eriksson, L, Granström. "Randomized controlled trial of appendicectomy versus antibiotic therapy for acute appendicitis" British journal of surgery. 1995, 82(2), pp. 166169

51] J, Styrud, S, Eriksson, I, Nilsson, G, Ahlberg, S, Haapaniemi, G, Neovius, L, Rex, I, Badume, L, Granström. "Appendectomy versus antibiotic treatment in acute appendicitis. a prospective multicenter randomized controlled trial" World journal of surgery. 2006, 30(6), pp.1033-1037.

[52] N, Chand, AJ, Sanyal. "Sepsis-induced cholestasis. Hepatology" 2007, 45(1), pp. 230-241.

[53] IG, Panagiotopoulou, D, Parashar, R, Lin, S, Antonowicz, AD, Wells, FM, Bajwa, B, Krijgsman. "The diagnostic value of white cell count, C-reactive protein and bilirubin in acute appendicitis and its complications" The Annals of the Royal College of Surgeons of England. 2013 95(3), pp. 215-221. 